\title{
Glandular and extraglandular expression of costimulatory molecules in patients with Sjögren's syndrome
} R Matsumura, K Umemiya, T Goto, T Nakazawa, M Kagami, H Tomioka, E Tanabe,
T Sugiyama, M Sueishi

act

Objectives-To investigate the expression molecules in sialoadenitis Sjögren's syndrome (SS).

Methods-Expression of CD80, CD86, and CD28 molecules was studied by immunohistochemical staining of lip biopsy specimens obtained from patients who had sialoadenitis associated with $\mathrm{SS}$, and renal biopsy specimens obtained from patients who had interstitial nephritis associated with SS. To elucidate the mechanism of de novo expression of CD80 and CD86 antigens, their induction by cytokines in human salivary duct cell line (HSG) and renal cortical epithelial cells (HRCE) by cell enzyme linked immunosorbent assay (ELISA) was quantitatively investigated. Results-In patients with severe sialoadenitis, CD80 and CD86 were strongly expressed on ductal epithelial cells. In contrast, these antigens were not found in the minor salivary glands of normal subjects or of patients with mild sialoadenitis. Some infiltrating cells expressed CD28. In patients who had interstitial nephritis associated with SS, some tubular epithelial cells expressed CD86 but not the CD80 antigen. Unstimulated HSG cells did not express CD80 or CD86. Interferon $\gamma($ IFN $\gamma)$ consistently up regulated levels of CD80 and CD86. In contrast, tumour necrosis factor $\alpha(\mathrm{TNF} \alpha)$, interleukin $1 \beta$ (IL1 $\beta$ ), IL2, and IL4 had no effect on either CD80 or CD86 levels. Unstimulated HRCE did not express CD80 or CD86. IFN $\gamma$ consistently up regulated CD86 expression. No CD80 expression was found on tubular cells. TNF $\alpha$, IL1 $\beta$, IL2, and IL4 had no discernible effects. Conclusions-Salivary ductal cells in patients with SS can express CD80 and CD86 costimulatory molecules in response to IFN $\gamma$. Tubular epithelial cells in patients who have interstitial nephritis associated with SS express only CD86 molecules. In patients with SS, salivary ductal cells and tubular epithelial cells may activate infiltrating CD28 positive $T$ lymphocytes by presenting antigens to $T$ cells, potentially leading to tissue destruction. (Ann Rheum Dis 2001;60:473-482)
Sjögren's syndrome (SS) is a chronic autoimmune disorder characterised by dysfunction and destruction of the salivary, lachrymal, and other exocrine glands. Histologically, marked infiltration of lymphoid cells is commonly found in the lachrymal and salivary glands. Most infiltrating lymphocytes are activated $\mathrm{CD} 4+\mathrm{T}$ cells $^{1}$ and produce cytokines such as interleukin 2 (IL2), interferon $\gamma$ (IFN $\gamma$ ), tumour necrosis factor $\alpha$ (TNF $\alpha)$, and IL $1 \beta .^{2341}$ Recently, several studies have shown that glandular epithelial cells, especially ductal cells in SS lesions, are activated and may play a part in induction and progression of the inflammatory process. ${ }^{4}$ Class II type major histocompatibility antigen (MHC) HLA-DR protein and intercellular adhesion molecules (ICAM-1) are also expressed on ductal epithelial cells in SS. ${ }^{5}$ We previously reported that ductal epithelial cells show aberrant Fas expression and apoptosis induced by Fas ligand of infiltrated cells. ${ }^{67}$

In some patients with SS, renal disease, especially interstitial nephritis, develops, possibly as a consequence of immunological renal injury. ${ }^{8}$ Histologically interstitial nephritis is characterised by interstitial mononuclear cell infiltration and interstitial oedema with fibrosis. These histological changes are similar to those in the salivary glands. ${ }^{9}$

In interstitial nephritis associated with SS, most infiltrating lymphocytes are activated $\mathrm{CD} 4+\mathrm{T}$ cells. ${ }^{10}$ Recently, several studies have reported that tubular epithelial cells in interstitial nephritis, both associated ${ }^{11}$ and not associated $^{12}$ with SS, express HLA-DR and ICAM-1 and may have a role in induction and progression of the inflammatory process.

The differentiation of activated $\mathrm{T}$ cells requires not only an antigen-specific signal mediated by the $\mathrm{T}$ cell receptor but also a costimulatory signal. ${ }^{13-15} \mathrm{~A}$ minor $\mathrm{T}$ cell costimulatory pathway involves surface interactions between the ICAM-1 on antigen-presenting cells (APC) and lymphocyte function associated antigen- 1 molecules on T cells. CD28 on $\mathrm{T}$ cells is thought to play an important part in the transmission of costimulatory signals. CD80 (B7.1) and CD86 (B7.2) molecules have been identified as CD28 ligands. Blockade of the B7-CD28 pathway in vitro results in $\mathrm{T}$ cell clonal anergy or in immunosuppression. ${ }^{16}$

CD80 and CD86 molecules have been reported to be expressed by specialised APC, including monocytes, macrophages, dendric cells, and activated B cells. Recently, however, 
some non-specialised APC, such as keratinocytes,${ }^{17}$ myocytes, ${ }^{18}$ vascular endothelial cells, ${ }^{19}$ synovial cells, ${ }^{2021}$ and peripheral $\mathrm{T}$ cells ${ }^{22}$ were also reported to express CD80 or CD86 molecules or both. Such expression of costimulatory molecules may be sufficient to induce primary $\mathrm{T}$ cell responses.

In SS, Manoussakis et al studied costimulatory molecules in lip biopsy specimens and in long term cultures of salivary glands obtained from patients with SS. ${ }^{30}$ CD 80 was strongly expressed on the surface of salivary gland epithelial cells in most patients. This aberrant expression of costimulatory molecules on salivary gland epithelial cells in SS may signify a central role of these cells in the immunopathogenesis of this disease. However, extraglandular expression of costimulatory molecules in SS remains unknown. The correlation between the histological grade of sialoadenitis and the grade of epithelial expression of costimulatory molecules was unclear in the study by Manoussakis et al.

Although aberrant costimulatory molecule expression has been reported, the mechanism inducing such expression remains unknown. Using immunoperoxidase cell enzyme linked immunosorbent assay (ELISA), ${ }^{23}{ }^{24}$ we quantitatively examined the expression of Fas antigen in salivary ductal cells stimulated by cytokines. A human salivary gland duct cell line (HSG) was established from an irradiated human submandibular salivary gland. ${ }^{25}$ It has characteristics of intercalated duct cells. HSG cells can mimic several features of SS disease in vivo. ${ }^{26}$ Cytokines such as IFN $\gamma$ and $\mathrm{TNF} \alpha$ induce increased expression of ICAM- 1 and HLA-DR in the HSG cell line. In addition, renal cortical epithelial cells (HRCE) were derived from normal human kidney and showed enzymatic properties of distal renal tubules. ${ }^{27}$ We used immunoperoxidase cell ELISA to investigate the CD80 and CD86 expression on HSG and HRCE stimulated by cytokines.

We sought to determine the cellular expression and distribution of CD80 and CD86 molecules in biopsy specimens of the salivary glands and kidney and investigated induction mechanisms for the ductal/tubular expression of these molecules.

\section{Patients and methods}

PATIENTS

The minor salivary glands of 20 patients (18 women, two men, aged 25-75 years, mean 49.4) with SS were studied. All patients had sicca symptoms with at least one of the following abnormalities: (a) keratoconjunctivitis sicca (positive results of Schirmer's test and rose bengal test), (b) lymphocytic infiltration of a specimen of the salivary gland obtained by lip biopsy, and (c) characteristic findings indicative of duct-acinar destruction on sialography. Secondary SS was diagnosed in two patients fulfilling the 1984 revised criteria for classification of systemic lupus erythematosus, two fulfilling the American Rheumatism Association criteria for rheumatoid arthritis, one fulfilling preliminary criteria for systemic sclerosis, and one fulfilling preliminary criteria for mixed connective tissue disease. ${ }^{28}$ The 14 other patients were given a diagnosis of primary SS. As control, normal minor salivary glands were obtained for diagnostic examination from four patients with fever of unknown origin; there were no abnormal changes in the lip biopsy specimens.

Renal biopsy specimens obtained from six patients (four women, two men, aged 44-66 years, mean 55.5) who had interstitial nephritis associated with SS were also studied. All patients had sicca symptoms, with at least one of the abnormalities described above. One patient fulfilling the criteria for systemic lupus erythematosus and one with rheumatoid arthritis were considered to have secondary SS. The other four patients were diagnosed as primary SS. At the time of the biopsies, no patients were undergoing any immunomodulative treatment with anti-inflammatory drugs and corticosteroids, except one patient who received $5 \mathrm{mg}$ prednisolone daily. As control, normal specimens of renal tissue obtained from the non-affected portions of surgically removed kidneys in four patients with renal cell carcinoma were examined. The control specimens showed minimal changes on light microscopic and immunofluorescence studiesnamely, mild shrinkage of the glomerular tuft probably owing to the ligation of the renal artery.

\section{IMMUNOPEROXIDASE STAINING}

Samples of minor salivary glands were obtained by lip biopsy. Tissue sections were prepared for immunoperoxidase staining as follows: $6 \mu \mathrm{m}$ thick cryostat sections were dried, fixed in acetone for 15 minutes at $4^{\circ} \mathrm{C}$, and rinsed with phosphate buffered saline (PBS). After treatment with normal goat serum, the sections were successively incubated in the following solutions washed with PBS: monoclonal antibody to CD80 (Immunotech, Marseille, France), CD86 (Ancell, MN, USA ), or CD28 (Dako Japan, Kyoto, Japan); Envision solution (peroxidase binding dextran polymer labelled with goat antimouse immunoglobulins; Dako Japan, Kyoto, Japan); $0.02 \% \quad 3,3$ '-diaminobenzidine containing $0.03 \% \mathrm{H}_{2} \mathrm{O}_{2}$ and $10 \mathrm{mM}$ sodium azide. The sections were subsequently stained with methyl green.

A surgically removed lymph node showing non-specific chronic lymphadenitis was used as a positive control. The following negative controls were used: (a) omission of primary antibody or (b) appropriately diluted mouse IgG as a first layer. In all negative controls, only a few granulocytes showed endogenous peroxidase activity.

\section{HISTOLOGICAL GRADING}

To assess inflammation in the salivary gland biopsy specimens, the number of focal aggregates including at least 50 mononuclear cells per gland was counted. We graded the ductal CD80 or CD86 expression according to the following criteria: no CD80 or CD86 expression, grade 0 ; CD80 or CD86 expression by a few ductal cells, grade 1; and CD80 or CD86 

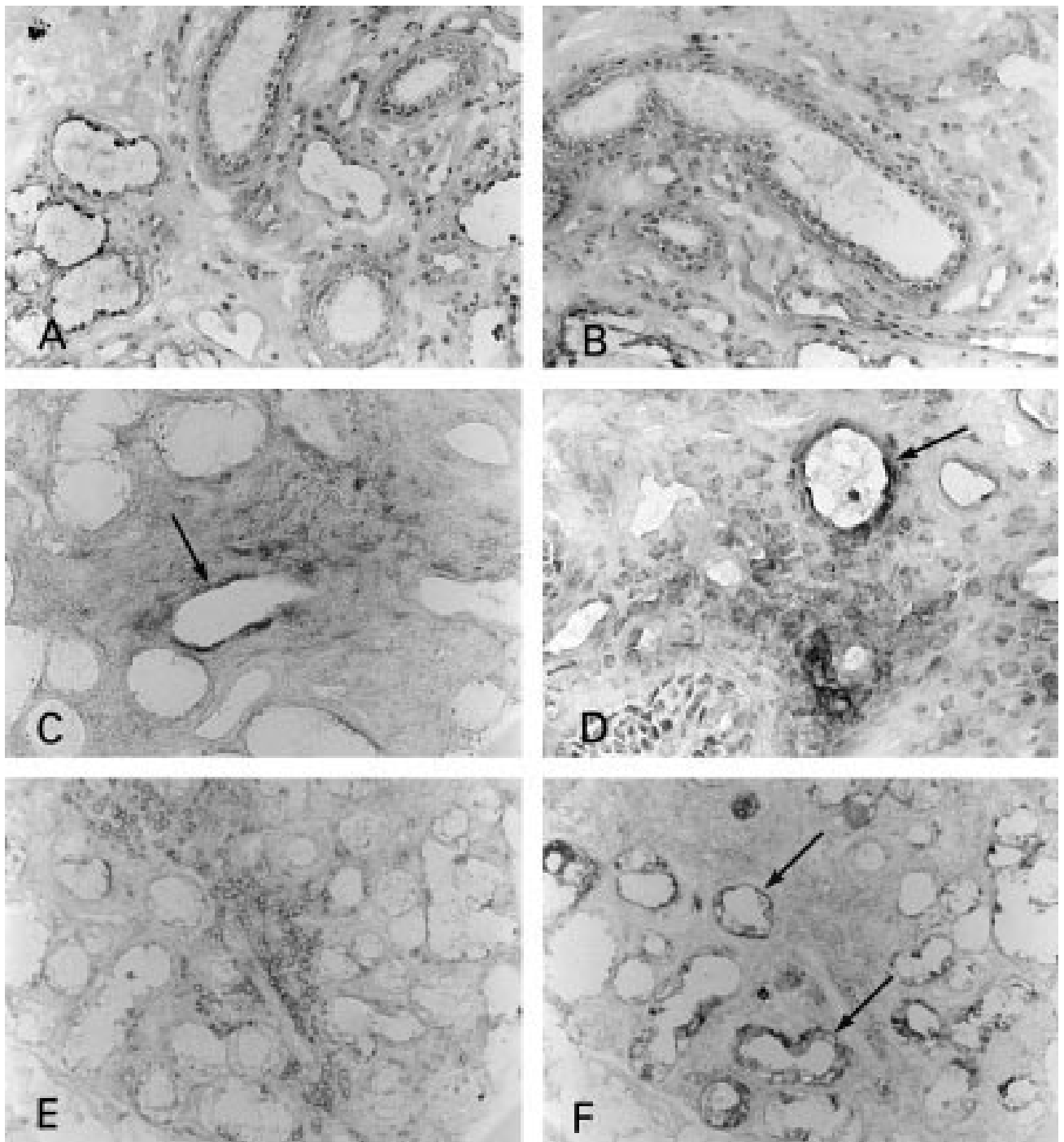

Figure 1 Immunohistochemical staining of CD80 and CD86 in the salivary gland. (A) CD80 was not seen in normal controls ( $\times 180)$; (B) CD86 was not seen in normal controls ( $\times 180)$; (C) CD80 on ductal epithelial cells (arrow) and some infiltrating mononuclear cells in severe sialoadenitis $(\times 180)$; (D) CD86 was expressed on ductal epithelial cells (arrow) and some infiltrating mononuclear cells in severe sialoadenitis ( $\times 360)$; (E) CD28 was seen on many infiltrating mononuclear cells in severe sialoadenitis around the duct expressing CD80; $(F)$ serial section of $(E)(\times 180)$.

expression by all cells of one duct or by many ductal cells, grade 2 .

TISSUE CULTURE

HSG cells (a gift from Dr Mitsunobu Sato, Tokushima University, Japan) were cultured in HAM F-12 Medium (Life Technologies, NY, USA) supplemented with $10 \%$ fetal calf serum (Biowhiffaker $\mathrm{MD}$, USA) at $37^{\circ} \mathrm{C}$ with $5 \%$ $\mathrm{CO}_{2}$.

HRCE cells purchased from Clonetics (San Diego, Ca, USA) were cultured in a renal epithelial cell growth medium bullet kit (Clonetics) at $37^{\circ} \mathrm{C}$ with $5 \% \mathrm{CO}_{2}$.

\section{TREATMENT OF CELLS WITH CYTOKINES}

Recombinant human IFN $\gamma$ (R\&D Systems, $\mathrm{MN}$, USA), recombinant human $\mathrm{TNF} \alpha$ (Pharmingen, CA, USA), recombinant human IL1 $\beta$ (R\&D Systems), human IL2 (Roche Diagnostics GmbH Mannheim, Germany), and recombinant human IL4 (Genzyme, MA, USA) were used. Cells were cultured in the presence of IFN $\gamma, 1-100 \mathrm{U} / \mathrm{ml}$; TNF $\alpha, 1-100$ $\mathrm{U} / \mathrm{ml}$; IL1 $\beta, 0.001-0.1 \mathrm{U} / \mathrm{ml}$; IL2, 0.02-2 $\mathrm{U} / \mathrm{ml}$; or IL4, 3-30 U/ml for 24 hours.

To examine the time course of CD80 or CD86 expression on HSG or HRCE, the cells were cultured in the presence of IFN $\gamma$ (100 $\mathrm{U} / \mathrm{ml}$ ) for 4-72 hours.

CELL ELISA

A total of $8 \times 10^{3}$ cells/well were seeded onto gelatin coated, 96 well, flat bottomed microtitre plates (Falcon 3072, Becton Dickinson, NJ, USA) in $0.2 \mathrm{ml}$ of medium. After reaching confluence ( 48 hours), the culture medium was replaced with $0.2 \mathrm{ml}$ of fresh medium containing various concentrations of cytokines and incubated for various periods of time at $37^{\circ} \mathrm{C}$ in $5 \% \mathrm{CO}_{2}$. The cultures were fixed with $3 \%$ paraformaldehyde in PBS containing $8 \%$ sucrose for 30 minutes at room temperature. Subsequent washing steps were performed with five changes of PBS with $0.05 \%$ Tween 20 (Wako Osaka, Japan). To avoid non-specific 
binding of antibodies, the assays were performed after pretreatment with PBS and 50\% Blockace (Yukizirushi, Sapporo, Japan). After washing, the fixed monolayer was incubated with $0.1 \mathrm{ml} /$ well of $5 \%$ normal goat serum PBS for one hour. The blocking solution was added with $0.4 \mathrm{mg}$ of mouse monoclonal antibody to CD80 (Immunotech) or with $2 \mathrm{mg}$ of mouse monoclonal antibody to CD86 (Ancell) for 120 minutes at $37^{\circ} \mathrm{C}$. After washing, the plates were treated with $0.1 \mathrm{ml} /$ well of Envision solution (peroxidase binding dextran polymer labelled with goat antimouse immunoglobulins, Dako Japan) for 75 minutes at room temperature. The plates were washed again and incubated with $0.1 \mathrm{ml}$ of 3,3',5,5'-tetramethyl benzidine (Dako Japan) for 10-30 minutes at room temperature. The plates were read on a microtitre plate reader (SLT Labinstruments, Salzburg, Austria) at $650 \mathrm{~nm}$. For the dose dependent, time course and blocking experiments, the data are reported as the optical density (OD) achieved in a given experiment (mean (SD) of triplicate wells) after subtracting the background $\mathrm{OD}$ of wells for the negative control. As positive control for the cell ELISA system, epithelial membrane antibody (Dako Japan) was used. The following negative controls were used: (a) omission of primary
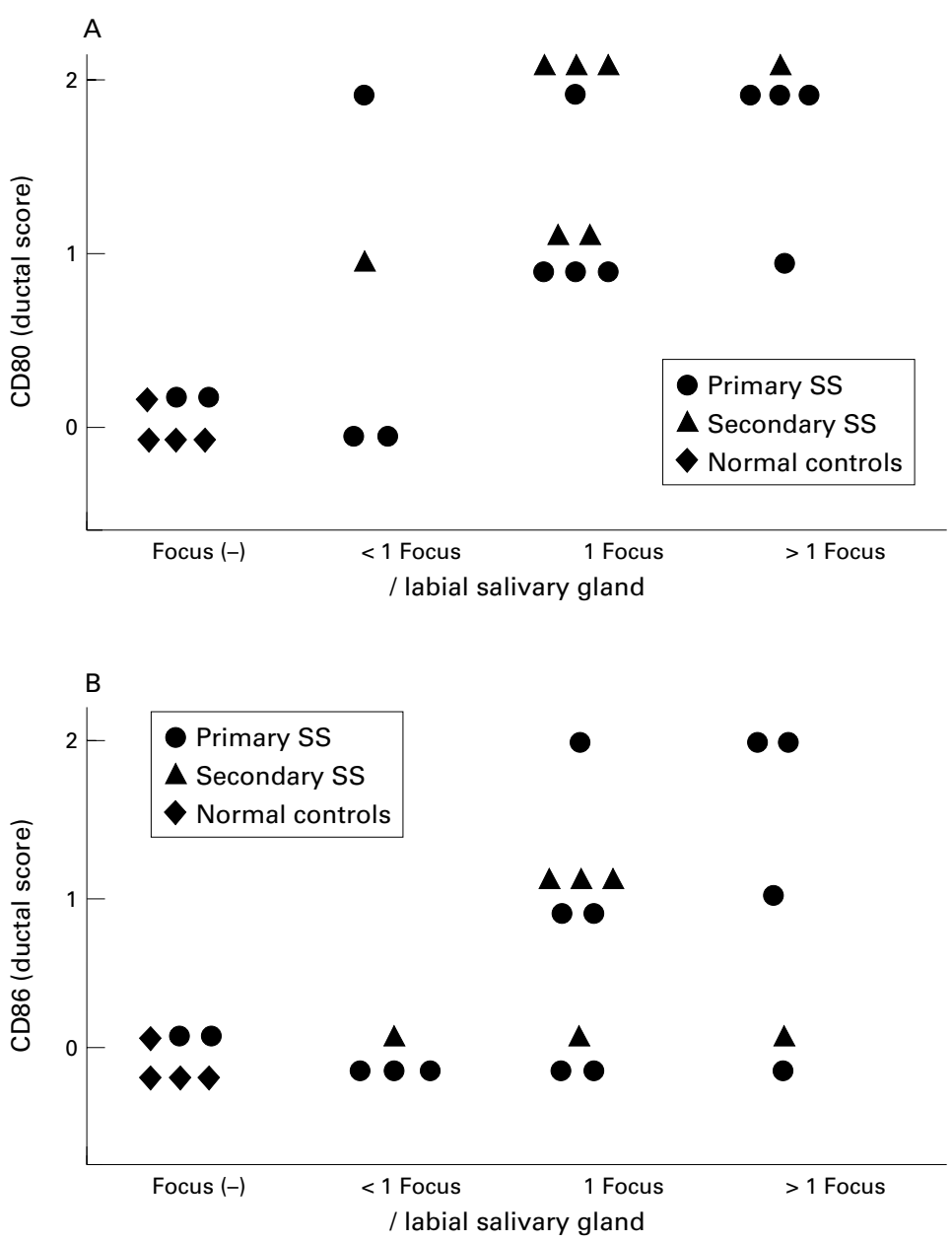

Figure 2 Ductal CD80 (A) and CD86 (B) expression and salivary gland lymphocytic infiltration. Ductal CD80 and CD86 expression was shown by the grading scale. CD80 and CD86 expression of ductal cells correlated with interstitial infiltration. $p<0.01$ in Spearman rank correlation. antibody or (b) appropriately diluted mouse $\mathrm{IgG}$ as a first layer.

STATISTICAL ANALYSIS

Cell ELISA data were analysed with Student's $t$ test.

IMMUNOPEROXIDASE STAINING OF CULTURED HSG AND HRCE ON SLIDE GLASS

A total of $1.6 \times 10^{4}$ cells/well were seeded onto Lab-Tek 11 chamber slides (Nunc, IL, USA) in $1 \mathrm{ml}$ of medium. After reaching confluence ( $\sim 48$ hours), the culture medium was replaced with $1 \mathrm{ml}$ of fresh medium with and without IFN $\gamma$ and incubated for 48 hours (HSG cells) or six hours (HRCE cells) at $37^{\circ} \mathrm{C}$ in $5 \% \mathrm{CO}_{2}$. To prepare for immunoperoxidase staining, the tissue sections were fixed with 3\% paraformaldehyde in PBS containing $8 \%$ sucrose for 30 minutes at room temperature, and rinsed with PBS. After treatment with normal goat serum, the sections were successively incubated with the following solutions, and washed with PBS: $0.8 \mathrm{mg}$ of monoclonal antibody to CD80 (Immunotech) or $2 \mathrm{mg}$ of monoclonal antibody to CD86 (Ancell), Envision solution (peroxidase binding dextran polymer labelled with goat antimouse immunoglobulins, Dako Japan), $0.02 \%$ 3,3'-diaminobenzidine containing $0.03 \% \mathrm{H}_{2} \mathrm{O}_{2}$ and $10 \mathrm{mM}$ sodium azide. The sections were subsequently stained with methyl green.

\section{Results}

CD80 AND CD86 EXPRESSION ON SALIVARY GLANDS IN PATIENTS WITH SS

In normal salivary glands, CD80 and CD86 were not expressed on either acinar cells or ductal cells (figs $1 \mathrm{~A}$ and B). No cells expressing CD28 were found in normal salivary glands. In patients who had SS with mild mononuclear cell infiltration and moderate interstitial fibrosis, CD80 was not expressed on minor salivary glands. In contrast, in patients with massive mononuclear cell infiltration, CD80 was expressed on ductal epithelial cells and a few acinar epithelial cells in the lip biopsy specimens (fig 1C). CD80 was seen on some infiltrating mononuclear cells of the minor salivary glands in all patients with SS. Ductal CD86 expression was also observed in patients who had massive mononuclear cell infiltration (fig 1D). In patients with mild mononuclear cell infiltration, CD86 was not expressed on minor salivary glands. CD86 positive cells were seen on some mononuclear cells infiltrating the minor salivary glands. Several CD28 positive cells (probably $\mathrm{T}$ cells) infiltrated (fig $1 \mathrm{E}$ ) around the CD80 (fig $1 F$ ) or CD86 positive ducts of the minor salivary glands. Ductal CD80 or CD86 expression was positively correlated with the grade of inflammation of the salivary glands (figs $2 \mathrm{~A}$ and $\mathrm{B}$ ). In severe lymphocytic infiltration, CD80 and CD86 expression was seen in many ductal cells. There was no difference in ductal CD80 and CD86 expression between primary and secondary SS. 

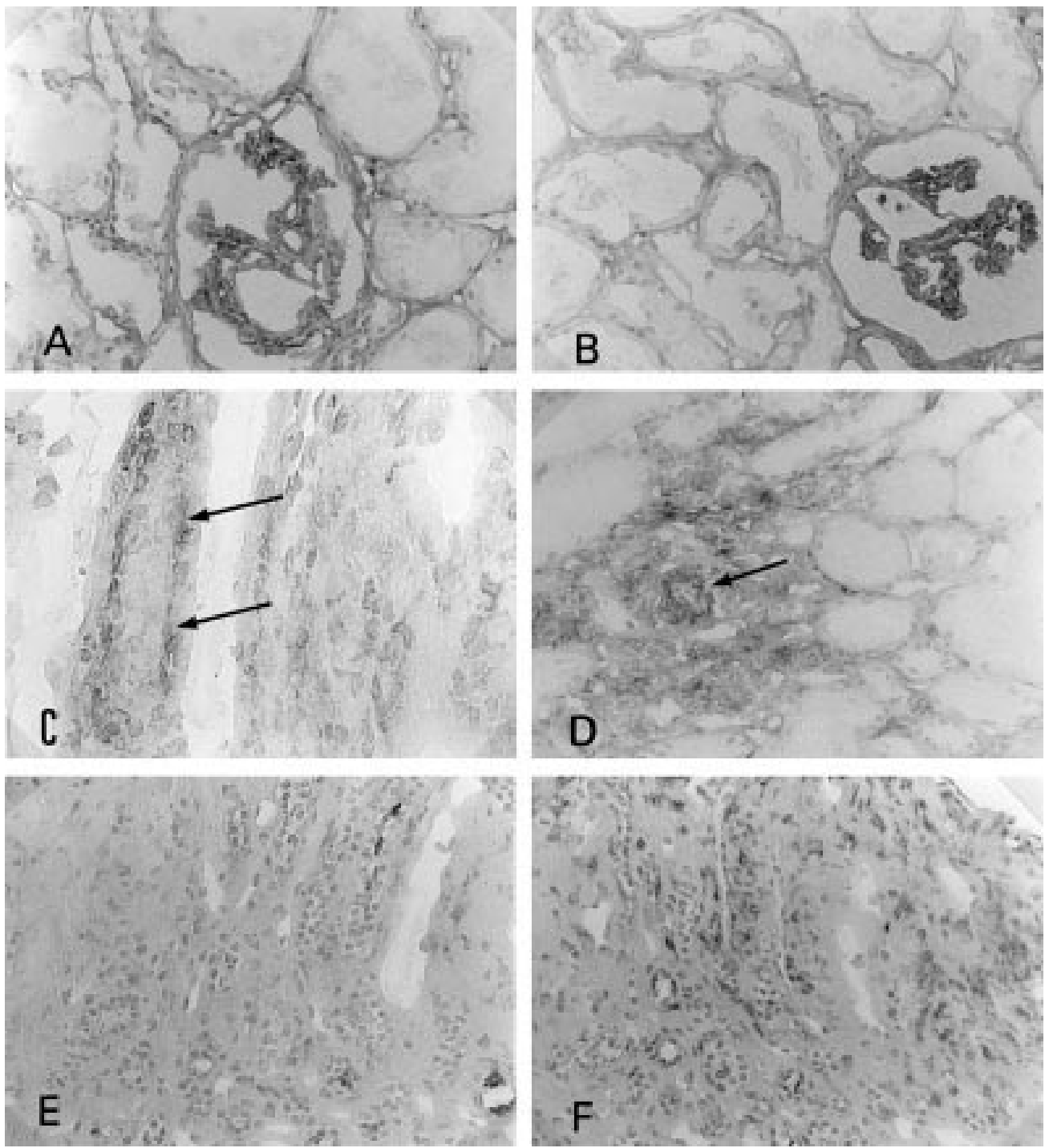

Figure 3 Immunostaining of CD80 and CD86 in the kidney. (A) CD80 was not seen on tubular epithelial cells in control tissue ( $\times 180)$; (B) CD86 was not seen on tubular epithelial cells in control tissue $(\times 180)$; (C) CD86 expression on tubular epithelial cells (basal side, arrows) in interstitial nephritis associated with Sjögren's syndrome (SS) $(\times 360)$; (D) the several tubular cells showed CD86 antigen in SS kidney (arrow) ( $\times 180)$; (E) CD80 was not seen on tubular epithelial cells in interstitial nephritis associated with SS $(\times 180) ;(F)$ CD28 expressed on some infiltrating cells (the same portion of the serial section of $(C)$ and $(E)(\times 180))$.

CD80 AND CD86 EXPRESSION IN INTERSTITIAL NEPHRITIS ASSOCIATED WITH SS

In the normal kidney, CD80 and CD86 were not expressed on tubular epithelial cells in normal control (figs $3 \mathrm{~A}$ and $\mathrm{B}$ ). No cells expressing CD28 were seen in normal renal interstitium. In five patients who had interstitial nephritis associated with SS, CD86 was expressed on tubular epithelial cells near the foci of mononuclear cell infiltration in renal biopsy specimens (figs 3C and D). Otherwise, few CD80 positive tubular cells were seen (fig 3E). CD80 or CD86 was seen on some infiltrating mononuclear cells in the renal interstitium of all patients with SS. Several CD28 positive cells were infiltrating (fig $3 \mathrm{~F}$ ) around the tubules in all cases. Figures 3C, E, and $\mathrm{F}$ show serial sections of the same case of interstitial nephritis. There was no distinct correlation between tubular CD86 expression and interstitial inflammation, probably because of the small number of cases examined.
EXPRESSION OF CD80 AND CD86 MOLECULES IN HSG CELL LINE

On immunohistochemical staining, CD80 and CD86 were not expressed on unstimulated HSG cells but were expressed on many HSG cells stimulated by $100 \mathrm{U} / \mathrm{ml}$ of IFN $\gamma$ (figs 4A, $\mathrm{B}, \mathrm{C}$, and D).

Using an immunoperoxidase cell ELISA, we found that unstimulated HSG cells did not express CD80 or CD86 molecules. IFN $\gamma$ $(1-100 \mathrm{U} / \mathrm{ml})$ consistently up regulated constitutively expressed levels of CD80 and CD86 in a dose dependent fashion (figs $5 \mathrm{~A}$ and $\mathrm{B}$ ). Figures $5 \mathrm{C}$ and $\mathrm{D}$ show the time courses of CD80 and CD86 expression induced by IFN $\gamma$. A significant increase in CD80 or CD86 expression was seen 48 hours after the addition of IFN $\gamma$ (100 U/ml).

To examine the specificity of IFN $\gamma$, we tested the ability of antibody to IFN $\gamma$ to block the expression of CD80 and CD86. Pretreatment of IFN $\gamma$ with anti-IFN $\gamma$ for 30 minutes before 

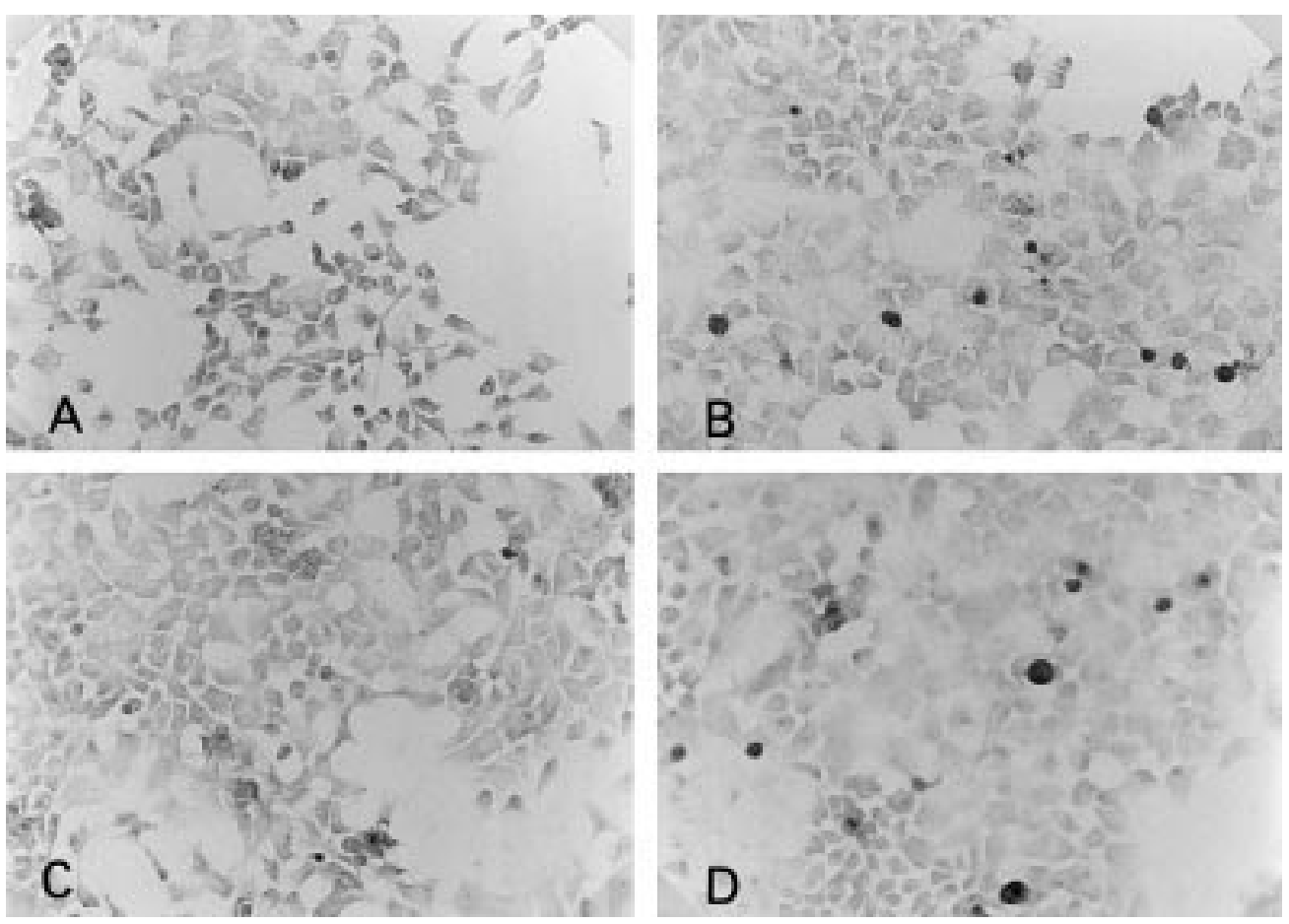

Figure 4 Immunohistochemical staining of anti-CD80 or CD86 antibody on cultured human salivary gland duct (HSG) cell line $(\times 180)$. Without cytokine stimulation, CD80 (A) or CD86 (B) expression was not seen on HSG. Many HSG cells stimulated by $100 \mathrm{U} / \mathrm{ml}$ of interferon $\gamma$ for 24 hours showed CD80 (C) or CD86 (D) expression.

stimulation resulted in a dose dependent elimination of the up regulation of CD80 and CD86 expression (figs $5 \mathrm{E}$ and $\mathrm{F}$ ).

Six to 48 hours' incubation with IL1 $\beta$, IL2, or IL4 did not influence the expression of CD80 and CD86 on HSG cells (data not shown).

EXPRESSION OF CD80 AND CD86 MOLECULES ON HRCE CELLS

On immunohistochemical staining, CD80 and CD86 were not expressed on unstimulated HRCE cells. CD86 expression was seen on many HRCE cells stimulated by $100 \mathrm{U} / \mathrm{ml}$ of IFN $\gamma$ (figs 6A, B, C, and D).

Using an immunoperoxidase cell ELISA, we found that unstimulated renal cortical epithelial cells did not express CD80 or CD86 molecules. IFN $\gamma(1-100 \mathrm{U} / \mathrm{ml})$ consistently up regulated constitutively expressed levels of CD86 in a dose dependent fashion (fig 7A). However, the levels of CD80 did not change in response to $\mathrm{IFN} \gamma(1-100 \mathrm{U} / \mathrm{ml})$ stimulation (fig $7 \mathrm{~B}$ ). Figure $7 \mathrm{C}$ shows the time course of CD86 expression induced by IFN $\gamma$. A significant increase in CD86 expression was seen 6-12 hours after the addition of IFN $\gamma$.

To examine the specificity of IFN $\gamma$, we tested the ability of antibody to IFN $\gamma$ to block the expression of CD86. Pretreatment of IFN $\gamma$ with antibody to IFN $\gamma$ for 30 minutes before stimulation with IFN $\gamma$ resulted in elimination of the up regulation of CD86 expression (fig 7D).

Six to 48 hours' incubation with IL1 $\beta$, IL2, or IL4 did not influence the expression of CD80 or CD86 on HRCE cells (data not shown).

\section{Discussion}

The role of costimulatory molecules in autoimmune diseases has received considerable attention. The expression of CD80 or CD86 molecules by APC infiltrating the synovia of patients with rheumatoid arthritis ${ }^{21}$ and skin lesions of patients with systemic lupus erythematosus ${ }^{17}$ has been recently described. The aberrant expression of CD80 or CD86 molecules by epithelial cells has been implicated in the pathogenesis of autoimmune disorders. Thyroid epithelial cells from patients with Graves's thyroiditis have been found to express CD80. ${ }^{29}$

For the first time, Manoussakis et al reported that CD80 was strongly expressed on the surface of salivary gland epithelial cells in most patients with SS and on long term cultures of salivary glands obtained from patients with SS. ${ }^{30}{ }^{31}$ However, extraglandular expression of costimulatory molecules in SS remains unknown. The correlation between the histological grade of sialoadenitis and the grade of epithelial expression of costimulatory molecules was unclear in this study. We therefore examined the expression of CD80 and CD86 molecules in sialoadenitis and interstitial nephritis, conditions affecting glandular and extraglandular organs respectively. We also studied the correlation of ductal CD80 and CD86 expression with the grade of sialoadenitis.

The induction and regulation of CD80 and CD86 expression on salivary ductal cells and tubular epithelial cells are thought to be the keys to in situ $\mathrm{T}$ cell activation associated with organ involvement in SS. Quantitative measurements of CD80 and CD86 expression on 

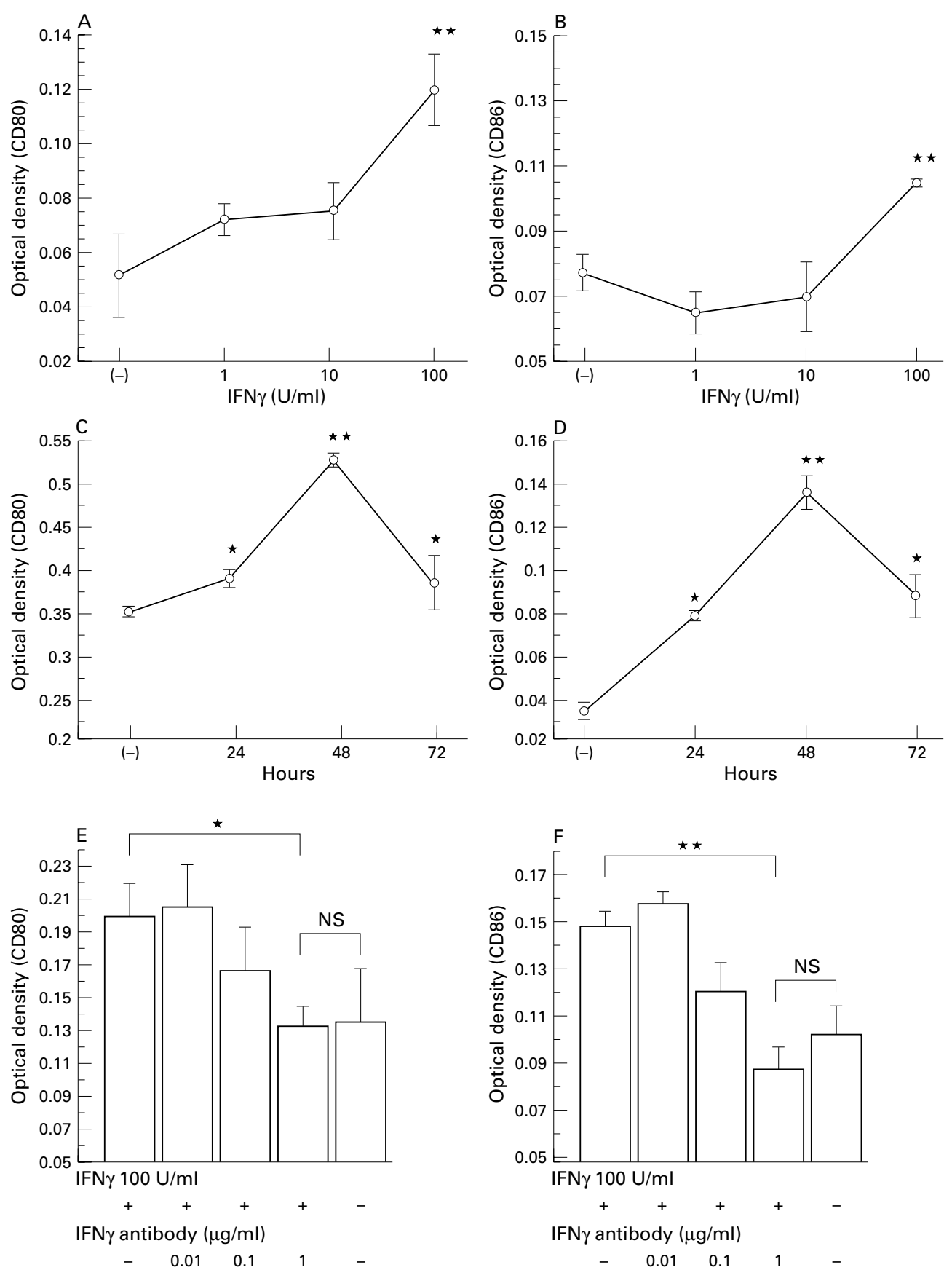

Figure 5 Effect of interferon $\gamma$ (IFN $\gamma$ ) on human salivary gland duct (HSG) CD80 or CD86 expression as measured by immunoperoxidase cell ELISA. Cells were cultured and stimulated with IFN $\gamma$. (A) CD80 expression after 24 hours' exposure to increasing concentrations of IFN ; $(B) C D 86$ expression after 24 hours' exposure to increasing concentrations of IFN $\gamma$; (C) time course of induction of CD80 by IFN (100 U/ml); (D) time course of induction of CD86 by IFN $(100$ U/ml); (E, F) effect of blockade of CD80 (E) and CD86 (F) expression by anti-IFN $\gamma$. HSG cells were cultured and

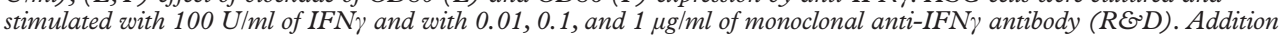
of $1 \mu \mathrm{g} / \mathrm{ml}$ of anti-IFN $\gamma$ inhibited the up regulation of IFN $\gamma$. All values are expressed as means (SD) of triplicate wells. $\star_{p}<0.05, \star_{p}<0.01$ indicate significant difference from the control (untreated) OD. Absence of an error bar indicates that the error was less than the symbol size.

these epithelial cells are therefore necessary. A variety of methods, including fluorescence activated cell sorter (FACS) and radioimmunoassay, have been used to measure cell surface antigen expression. Cell ELISA was compared with immunofluoresence staining by Grunow et $a l^{23}$ and both assays were found to be similarly sensitive. CD4 positive and CD4 negative cell lines were mixed at different cell ratios. Anti-CD 4 curves in the cell ELISA and mean immunofluorescence intensities both reached cut off values at a cell ratio of $12.5 \%$. Those results underline the advantage of cell ELISA for antigen detection. In contrast to FACS and radioimmunoassay, our approach avoids mechanical disruption of cell monolayer, trypsinisaton, and the use of radioactivity.

In severe sialoadenitis in patients with SS, ductal epithelial cells expressed aberrant CD80 and CD86 molecules. Ductal expression was correlated with interstitial cellular infiltration. Human salivary ductal cells stimulated by 

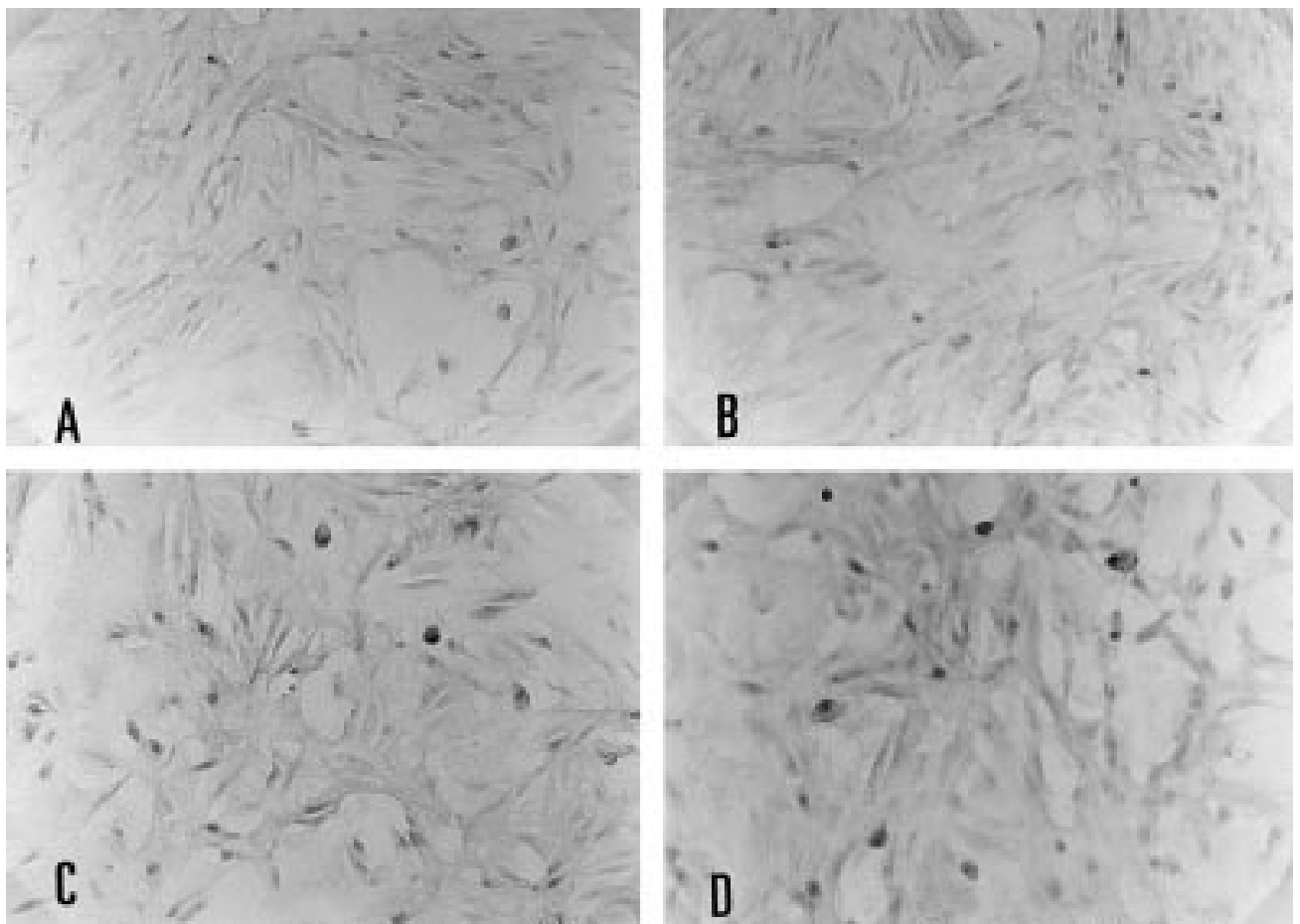

Figure 6 Immunohistochemical staining of anti-CD80 or CD86 antibody on cultured renal cortical epithelial cells (HRCE) cells $(\times 180)$. Without cytokine stimulation, CD80 (A) expression was not seen on HRCE and a few CD86 positive cells were seen (C). CD80 expression was not induced by interferon $\gamma($ IFN $\gamma)(B)$. Many HRCE cells stimulated by $100 \mathrm{U} / \mathrm{ml}$ IFN $\gamma$ for 24 hours showed only CD86 (D) expression.

IFN $\gamma$ showed CD80 and CD86. Therefore, IFN $\gamma$ secreted by infiltrating lymphocytes in salivary tissue can induce CD80 and CD86 expression by ductal cells. This aberrant expression of CD80 and CD86 may activate T cells around the ducts. Activated T cells reacting with antigen on ductal cells might destroy the salivary tissues by Fas-Fas ligand system or perforin mechanism. ${ }^{7}$ Some activated $\mathrm{T}$ cells may produce cytokines such as IFN $\gamma$. Fox et al reported that TNF $\alpha$, IL1 $\beta$, IL2, IL4, IL6, and IL10 were secreted in salivary glands in addition to IFN $\gamma .{ }^{2}$ In contrast, IL $1 \beta$, IL2, IL4, and granulocyte macrophage colony stimulating factor did not influence the levels of CD80 and CD86 in salivary ductal cells.

In interstitial nephritis associated with SS, tubular epithelial cells expressed only CD86. Human tubular epithelial cells stimulated by IFN $\gamma$ showed only CD86. The expression of costimulatory molecules on tubular epithelial cells has been controversial. Hagerty reported that tubular cells of MRL-lpr mouse did not express CD80 or CD86 antigens on fluorescence cytometry. ${ }^{32}$ CD80 and CD86 were not found on human tubular cells by Schulz et al. ${ }^{33}$ On the other hand, Banu and Meyers reported that IFN $\gamma$ and lipopolysaccharide differentially modulate CD80 expression on murine renal tubular epithelial cells. ${ }^{34}$ These disparate results may arise from differences in mouse strains and in monoclonal antibodies to costimulatory molecules. There were also some methodological differences. Hagerty and Schulz et al used trypsin to prepare single cell suspensions of tubular cells, whereas Banu and Meyers used cold EDTA. We therefore used cell ELISA for assay of CD80 and CD86 expression to avoid mechanical disruption of cell monolayer and trypsinisaton.

Aberrant HLA-DR and ICAM-1 molecules are expressed on tubular epithelial cells in interstitial nephritis associated with SS. ${ }^{11}$ In patients with SS who had interstitial nephritis, tubular epithelial cells expressed aberrant CD86 molecules. Human tubular cells stimulated by IFN $\gamma$ showed CD86. Therefore, IFN $\gamma$ secreted by lymphocytes infiltrating renal tissue can induce CD86 expression by tubular cells. This aberrant expression of CD86 may activate $\mathrm{T}$ cells around the tubules.

Available evidence thus indicates that the expression of CD80 or CD86 molecules by SS epithelial cells involves intracellular activation processes. Specific expression of CD80 or CD86 by the salivary and tubular epithelial cells of patients with SS provides evidence that these cells function as APC in the development of the lymphocytic infiltration that characterises the disease.

Functional differences between CD80 and CD86 have received attention. Kuchroio et al reported that costimulation of CD80 differentially activates the Th 1 development pathway. ${ }^{35}$ Freeman et al suggested that CD86 but not CD80 preferentially costimulates the initial production of IL4. ${ }^{36}$ However, CD80 and CD86 were reported to stimulate similar patterns of cytokine secretion by Levine et al. ${ }^{37}$ Azuma et al found that CD86 costimulation was more important than CD80 costimulation and suggested that monocytes that constitutively express CD86 but not CD80 act as the predominant APC. ${ }^{38}$ On costimulation with 

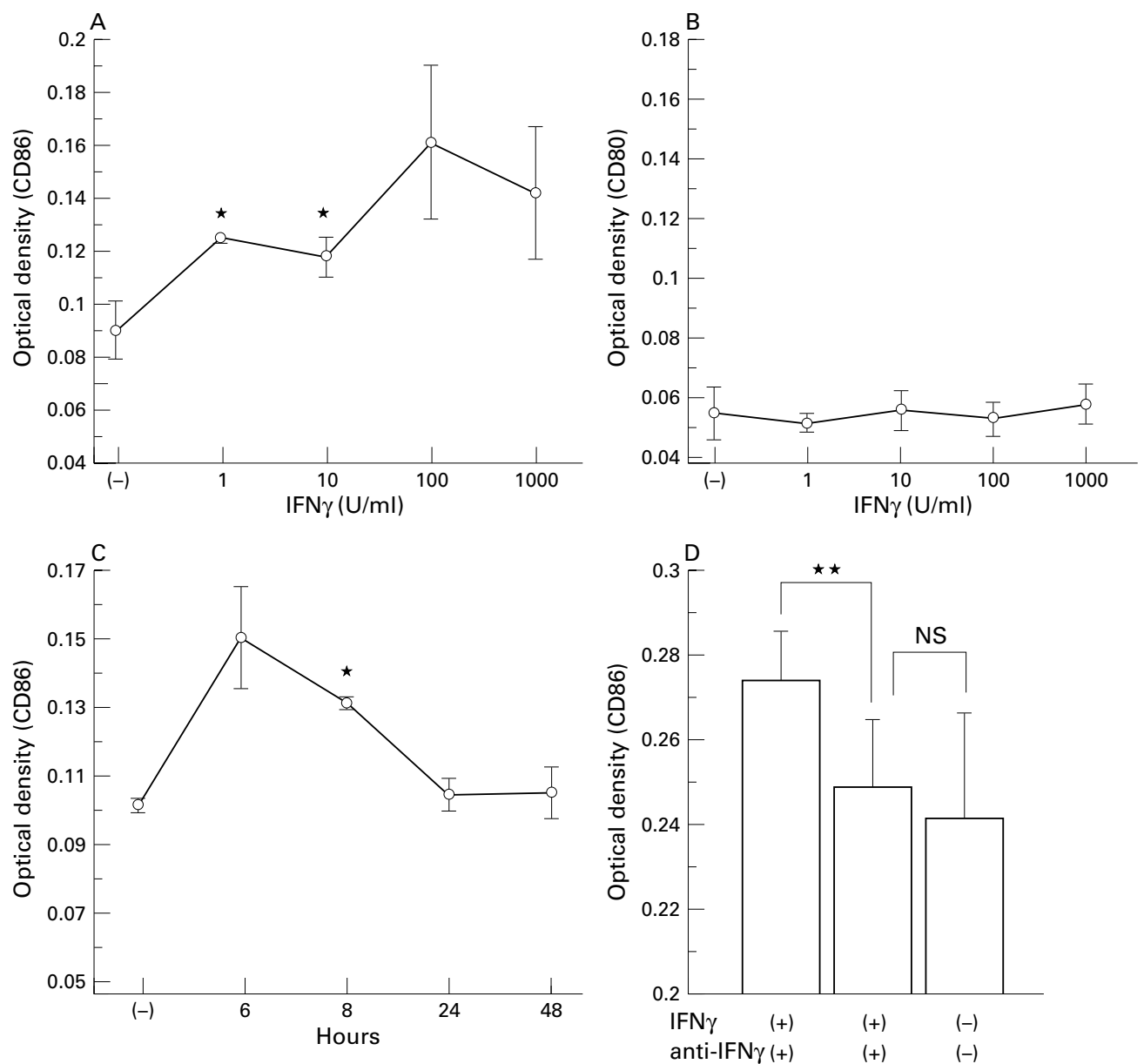

Figure 7 Effect of interferon $\gamma$ (IFN $\gamma$ ) in CD80 or CD86 expression on renal cortical epithelial (HRCE) cells as measured by immunoperoxidase cell ELISA. Cells were cultured and stimulated with IFN $\gamma$. (A) CD86 expression after 12 hours' exposure to increasing concentrations of IFN ; (B) CD80 expression was not induced by 12 hours' exposure to

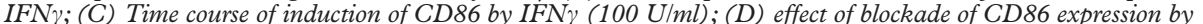
anti-IFN $(a-I F N)$. HRCE cells were cultured and stimulated with $100 \mathrm{U} / \mathrm{ml}$ of IFN $\gamma$ and $1 \mu \mathrm{g} / \mathrm{ml}$ polyclonal anti-IFN (Genzyme). Addition of $1 \mu \mathrm{g} / \mathrm{ml}$ of anti-IFN $\gamma$ inhibited the up regulation of $I F N \gamma$. All values are expressed as means (SD) of triplicate wells. ${ }^{\star} p<0.05,{ }^{\star} p<0.01$ indicate a significant difference from control (untreated) OD. No error bar indicates that the error was less than the symbol size.

non-specialised APC, vascular endothelial cells principally expressed CD86 in the culture medium, and anti-CD86 monoclonal antibody induced no response in $\mathrm{T}$ cells stimulated by endothelial cells. ${ }^{19}$ However, the functional differences between CD80 and CD86 in SS remain unknown.

Murata et al reported that the repertoire of the $\mathrm{T}$ cell receptor $\mathrm{Vb}$ gene on $\mathrm{T}$ cells infiltrating the kidneys of patients with SS who have interstitial nephritis is more restricted than that of peripheral blood lymphocytes. ${ }^{39}$ The same $\mathrm{Vb} 2$ clones as those found in the kidney were not detected in the labial salivary glands of the same patients with SS. They concluded that T cells infiltrating the kidneys of patients who have SS with interstitial nephritis might recognise different autoantigen ${ }^{40}$ from those infiltrating the labial salivary glands. In our study, tubular epithelial cells showed only CD86 protein, whereas salivary ductal cells expressed both CD80 and CD86. Interstitial nephritis is a major extraglandular disease that does not develop in most patients with SS. In patients with renal tubules that express CD86 molecules in response to activation by IFN $\gamma$, tubular epithelium might activate $\mathrm{T}$ cells through interactions between $\mathrm{MHC}+$ tubular antigen (?) and $\mathrm{T}$ cell receptor, associated with CD86 and CD28 binding.

In conclusion, salivary ductal cells and tubular epithelial cells in patients with SS can express CD80, CD86, or both. Such epithelial cells may be suitably equipped for the presentation of antigens to CD28-expressing $\mathrm{T}$ lymphocytes as well as MHC molecule expression after activation. Whether CD80 and CD86 molecules expressed by salivary ductal and tubular epithelium can provide optimal costimulation remains to be established. Further functional studies of costimulatory molecules in SS may lead to the identification of mechanisms responsible for organ involvement and to the development of new treatment for SS.

This work was partially supported by a grant from the Clinical Research Division of National Shimoshizu Hospital.

\footnotetext{
1 Adamson TC, Fox RI, Frisman DM, Howell FV. Immunohistologic analysis of lymphoid infiltrates in primary Sjögren's syndrome using monoclonal antibodies. J ImmuSjögren's syndrome

2 Fox RI, Kang H, Ando D, Abrams J, Pisa E. Cytokine mRNA expression in salivary gland biopsies of Sjögren's syndrome. J Immunol 1994;152:5532-9.
} 
3 Oxholm P, Daniels TE, Bendtzen K. Cytokine expression in labial salivary glands from patients with primary Sjögren's

4 Katz J, Nagler R, Barak S, Livneh AV, Baum B, Atkinson J, et al. Cytokines modulate interleukin- 6 production by human salivary gland cell line. Cell Immunol 1994;159 211-14.

5 Moutsopoulos HM, Hooks JJ, Chan CC, Dalavanga YA, Skopouli FN, Detrick B, et al. HLA-DR expression by labial minor salivary gland tissues in Sjögren's syndrome. Ann Rheum Dis 1986;45:677-83.

6 Matsumura R, Kagami M, Tomioka T, Tanabe E, Sugiyama $\mathrm{T}$, Sueishi M, et al. Expression of ductal Fas antigen in sialoadenitis of Sjögren's syndrome. Clin Exp Rheumatol 1996;14:309-11.

7 Matsumura R, Umemiya K, Kagami M, Tomioka $\mathrm{H}$, Tanabe E, Sugiyama T, et al. Glandular and extraglandular expression of Fas-Fas ligand and apoptosis in patients with expression of Fas-Fas ligand and apoptosis in patients with

8 Gerhardt RE, Loebl DH, Rao RN. Interstitial immunofluorescence in nephritis of Sjögren's syndrome. Clin Nephrol rescence in nephrit

9 Spencer RT, Arend WP, Emlen W. Systemic sclerosis, rheumatoid arthritis, Sjögren's syndrome, and polymyositisdermatomyositis. In: Schrier RW, Gottschalk CW, ed. Diseases of the kidney. 6th ed. Vol 2. Boston: Little, Brown, 1997:1813-15

10 Matsumura R, Kondo Y, Sugiyama T, Sueishi M, Koike T, Takabayashi $\mathrm{K}$, et al. Immunohistochemical identification of infiltrating mononuclear cells in tubulointerstitial nephritis associated with Sjögren's syndrome. Clin Nephrol 1988;30:335-40

11 Matsumura R, Umemiya K, Nakazawa T, Ochiai K, Kagami $\mathrm{M}$, Tomioka $\mathrm{H}$, et al. Expression of cell adhesion molecules in tubulointerstitial nephritis associated with Sjögren's syndrome. Clin Nephrol 1998;49:74-81.

12 Benson EM, Colvin RB, Russell PS. Induction of Ia antigens in murine renal transplants. J Immunol 1985;134: antigens.

13 Mueller D, Jenkins MK, Schwartz R. Clonal expansion versus functional clonal activation: a costimuatory signaling
pathway determines the outcome of $T$ cell antigen receptor pathway determines the outcome of T cell antige
occupancy. Ann Rev Immunol 1989;7:445-80.

14 Thompson CB, Lindsten T, Ledbetter JA, Kunkel SL, Young HA, Emerson SG, et al. CD28 activation pathway regulates the production of multiple T-cell derived lymphokines/cytokines. Proc Natl Acad Sci USA 1989;86: 1333-7.

15 Schwartz RH. A cell culture model for T lymphocyte clonal anergy. Science 1990;248:1349-56.

16 Harding FA, McArthur JG, Gross JA. CD-28 mediated signaling co-stimulates murine $\mathrm{T}$ cells and prevents induction of anergy T-cell clones. Nature 1992;356:607-9.

17 Denfeld RW, Kind P, Sontheimer RD, Schoaf E, Simon TC. In situ expression of B7 and CD28 receptor families in skin lesion of patients with lupus erythematosus. Arthritis Rheum 1997;40:814-21.

18 Sugiura T, Murakawa Y, Takeuchi H, Imaoka K, Kondo M, Kobayasi S. Expression of adhesion molecules in inflamKobayasi S. Expression of adhesion molecules in inflammatory myopath

19 Seino K, Azuma M, Bashuda H, Fukao K, Yagita $H$, Okumura K. et al. CD86 (B70/B7-2) on endothelial cells co-stimulates allogeneic CD4+ T cells. Int Immunol 1995; 7:1331-7.

20 Liu MF, Kohsaka H, Sakurai H, Azuma M, Okumura K, Saito $\mathrm{H}$, et al. The presence of costimulatory molecules CD80 and CD28 in rheumatoid arthritis synovium. Arthritis Rheum 1996;39:110-14.

21 Balsa A, Dixey J, Sansom DM Maddison PF, Hall ND. Differential expression of the costimulatory molecules B7.1 and B7.2 in rheumatoid synovial tissue. $\mathrm{Br}$ J Rheumatol 1996;35:33-7.

22 Takasaki Y, Ogaki M, Abe K, Takeuchi K, Ando S, Takano $\mathrm{Y}$, et al. Expression of costimulatory molecule CD80 on peripheral blood $\mathrm{T}$ cells in patients with systemic lupus peripheral blood T cells in patients with system
23 Grunow R, D'Apuzzo M, Wyss-Coray T, Frutig K, Pichler WJ. A cell surface ELISA for screening of monoclonal anti-
bodies to antigens on viable cells in suspension. J Immunol bodies to antigens on viable

24 Winisky AP, Foster CA. ICAM-1 expression in a spontaneously transformed human keratinocyte cell line: characterization by a simple cell-ELISA assay. J Invest Dermatol 1992;99:48-52.

25 Shirasuna K, Sato M, Miyazaki T. A neoplastic epithelial duct cell line established from an irradiated human salivary gland. Cancer 1981;48:745-52.

26 Wu AJ, Kurrasch RH, Katz J, Fox PC, Baum BJ, Atkinson $\mathrm{JC}$, et al. Effect of tumor necrosis factor- $\alpha$ and interferongamma on the growth of a human salivary gland cell line. J Cell Physiol 1994;161:217-26.

27 Trifillis A, Regec AL, Trump BF. Isolation, culture and characterization of human tubular cells. J Urol 1985;133: 324-9.

28 Sharp GC, Irvin WS, Tan EM, Gould RG, Holman HR. Mixed connective tissue disease - an apparently distinct rheumatic disease syndrome associated with a specific antibody to an extractable nuclear antigen (ENA). Am J Med 1972;52:148-59.

29 Garcia-Cozar FJ, Lopez-Beltran A, Molina IJ, Benito P, Pena J, Santamaria M. Aberrant expression of the B7/BB1 antigen on thyroid cells of Graves-Basedow disease (GB); induction of B7 in thyroid cells which are not autoimmune [abstract]. Immunologia 1996;12:32.

30 Manoussakis MN, Dimitriou ID, Kapsogeorgou DE, Xanthou G, Paikos S, Polihronis M, et al. Expression of B7 costimulatory molecules by salivary gland epithelial cells in patients with Sjögren's syndrome. Arthritis Rheum 1999; 42:229-39.

31 Polihronis M, Tapinos NI, Theocharis SE, Economou A, Kittas C, Moutsopoulos HM. Modes of epithelial cell death and repair in Sjögren's syndrome. Clin Exp Immunol 1998;114:485-90.

32 Hagerty DT. Intercellular adhesion molecule-1 is necessary but not sufficient to activate CD4+ T cells. J Immunol 1996;156:3652-9.

33 Schulz H, Karau A, Filsinger S, Schoels M, Kabelitz D, Richter R, et al. Tubular epithelial cells as accessory cells for superantigen-induced T cell activation. Exp Nephrol 1998; 6:67-73.

34 Banu N, Meyers CM. IFN-gamma and LPS differentially modulate class II MHC and B7-1 expression on murine renal tubular epithelial cells. Kidney Int 1999;55:2250-63.

5 Kuchroio VK, Das MP, Brown JA, Ranger AM, Zamvil SS, Sobel RA, et al. B7-1 and B7-2 costimulatory molecules activate differentially the Th1/Th2 developmental pathways: application to autoimmune disease therapy. Cell 1995;80:707-18.

36 Freeman GJ, Boussiotis VA, Anumanthan A, Berstein BM, Ke XY. B7-1 and B7-2 do not deliver identical costimulatory signals, since B7-2 but not B7-1 preferentially costimulates the initial production of IL-4. Immunity 1995;2:523-32.

37 Levine BL, Ueda Y, Craighead N, Huang ML, June CH. CD28 ligands CD80 (B7-1) and CD86 (B7-2) induce long-term autocrine growth of CD $4+\mathrm{T}$ cells and induce long-term autocrine growth of CD4+ T cells and induce 1995;7:891-904

38 Azuma M, Ito D, Yagita H, Okumura K, Phillips JH, Lanier LL, et al. B70 antigen is a second ligand for CTLA-4 and CD28. Nature 1993;366;76-9.

39 Murata H, Kita Y, Sakamoto A, Matumoto I, Matsumura R, Sugiyama T, et al. Limited TCR repertoire of infiltrating T cells in the kidneys of Sjögren's syndrome patients with interstitial nephritis. J Immunol 1995;155:4084-9.

40 Sumida T, Yonaha F, Maeda E, Tanabe E, Koike T, Tomioka $\mathrm{H}$, et al. $\mathrm{T}$ cell receptor repertoire of infiltrating $\mathrm{T}$ cells in lip of Sjogren's syndrome patient. J Clin Invest 1992;89:681-5.

41 Boumba D, Skopouli FN, Moutsopoulos HM. Cytokine mRNA expression in the labial salivary gland tissues from patients with primary Sjögren's syndrome. Br J Rheumatol patients with prim 